\title{
An unusual association of os odontoideum compressive synovial cyst and multiple sclerosis: case report and review of the literature
}

\begin{abstract}
Background: Os odontoideum is a rare cervical abnormality that harbors a potential risk for atlantoaxial instability. In symptomatic cases, atlantoaxial stabilization is usually recommended. In rare circumstances, synovial cysts may develop and compromise the spinal cord. Therefore, cyst excision has been suggested as part of the surgical management. However, it has been shown recently that atlantoaxial stabilization alone might be sufficient for synovial cyst regression.
\end{abstract}

Methodology: 48-year-old woman presented with signs and symptoms of cervical myelopathy secondary to os odontoideum with atlantoaxial instability. A large synovial cyst was diagnosed with significant spinal cord compression. In addition, her spinal and cranial imaging was suggestive of multiple sclerosis (MS) which was confirmed clinically thereafter with one episode of MS flare up and positive cerebrospinal fluid analysis.

Results: After she had recovered from her MS flare up, posterior atlantoaxial instrumentation and fusion was performed without synovial cyst resection. Postoperatively, her clinical condition improved substantially and complete regression of the synovial cyst was noted on cervical MRI. Interestingly, she has not had any MS recurrent episodes after the surgery.

Conclusion:Degenerative changes in os odontoideum are consequences of atlantoaxia instability. Compressive synovial cysts may develop with associated cord compression. We recommend posterior atlantoaxial stabilization alone in such conditions while preserving cyst fenestration or excision for persistent symptoms related to unresolved synovial cysts.

Keywords: os odontoideum, synovial cysts, synchondrosis, chondral, atlantoaxial, sclerotome, synovium
Volume 5 Issue 4 - 2016

\author{
Ahmed Al Jishi, Tracy Watson, Ali Elgheriani, \\ Edward Kachur,Aleksa Cenic \\ Department of Surgery, McMaster University, Canada
}

Correspondence: Ahmed Al Jishi, Hamilton General Hospital, McMaster University, 237 Barton St East, Hamilton, ON, L8L 2X2, Canada, Tel + I(905) 52I-2I00; 447I2, Fax + I (905) 522 26I5,Emaildr_aljishi@yahoo.com

Received: November 22, 2016 | Published: December 09, 2016

\section{Introduction}

Os odontoideum is a rare atlantoaxial abnormality that affects the odontoid process. It has been proposed to be a congenital anomaly due to lack of chondral tissue or failed ossification along the growth line of the proatlas and the first spinal sclerotome, which are the precursors for the future odontoid process. ${ }^{1}$ Some authors have argued against this theory and believe that os odontoideum is likely a result of previous trauma with non-union of the healed fracture, hence, mimicking a type-II odontoid fracture. ${ }^{2}$ This was based on frequent radiological findings of non-union above the superior articular facets of the axis, a location that is above the synchondrosis line. Nevertheless, the ultimate result is an isolated rostral ossicle that can move with the anterior arc of $\mathrm{C} 1$ (orthotopic) or functionally fused to the basion (dystopic). ${ }^{3}$

An unusual pathological abnormality that is rarely seen in os odontoideum is the presence of a synovial cyst. In this manuscript, we describe a patient who presented with os odontoideum and a giant synovial cyst but with a more baffling scenario of concomitant multiple sclerosis. We consider this case as an example to support treating atlantoaxial instability as the main problem without the need for cyst excision.

\section{Case presentation}

A 48-year-old woman presented with a two-month history of insidious onset of neck pain, paresthesia and right leg weakness, which progressed to affect her hands. Besides her dexterity dysfunction, her legs became progressively stiffer with worsening of gait. There was no history of previous trauma. On examination, she was myelopathic with significant hyper-reflexic signs including Hoffman's sign and Babinski's signs bilaterally. Cervical spine imaging had shown an os odontoideum with thickened ligaments and large synovial cyst compressing the spinal cord (Figure 1). In addition, multiple T2 hyperintense foci were noticed through her cervical and thoracic cord. This was suspicious for possible concomitant autoimmune disease. Hence, an MRI of the brain was performed which was concerning for Multiple Sclerosis (MS) (Figure 2). A CSF analysis had confirmed the diagnosis with the presence of positive oligoclonal bands and an elevated $\operatorname{IgG}$ index.

Dynamic neck radiographs had shown atlantoaxial instability with $12 \mathrm{~mm}$ anterolisthesis. Owing to the nature of her instability and worsening symptoms, atlantoaxial stabilization was planned without excising the cyst. Two weeks prior to her surgery, she presented with a flare up of her MS and severe right leg weakness. She improved significantly after a short course of intravenous methylprednisolone and was never prescribed any other anti-MS medications thereafter. Eventually, she underwent posterior trans-articular atlantoaxial instrumentation and fusion. After four months, the patient showed significant improvement in her symptoms and functional competency. Postoperative MRI had shown complete regression of the synovial cyst (Figure 3). At ten months follow up, her clinical condition remained stable with absence of myelopathic signs, no recurrent MS attacks and lack of synovial cyst on repeated imaging. 

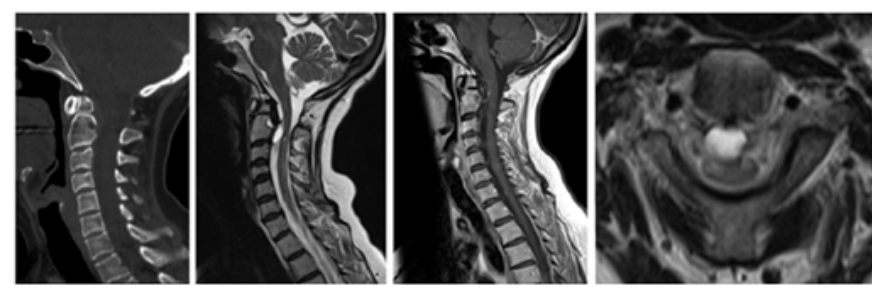

Figure I A CT scan of the cervical spine demonstrates an os odontoideum with dorsal osteolytic dens related to degenerative joint space.

A.The MRI showed a synovial cyst with rostral and ventral extension.

B.A cyst wall showed some enhancement after gadolinium infusion.

C. Note the significant mass effect over the spinal cord along with cord signal hyper-intensity adjacent to the cyst level as well as across the caudal cervical cord.

D. [C: Cyst, SP: Spinal cord].
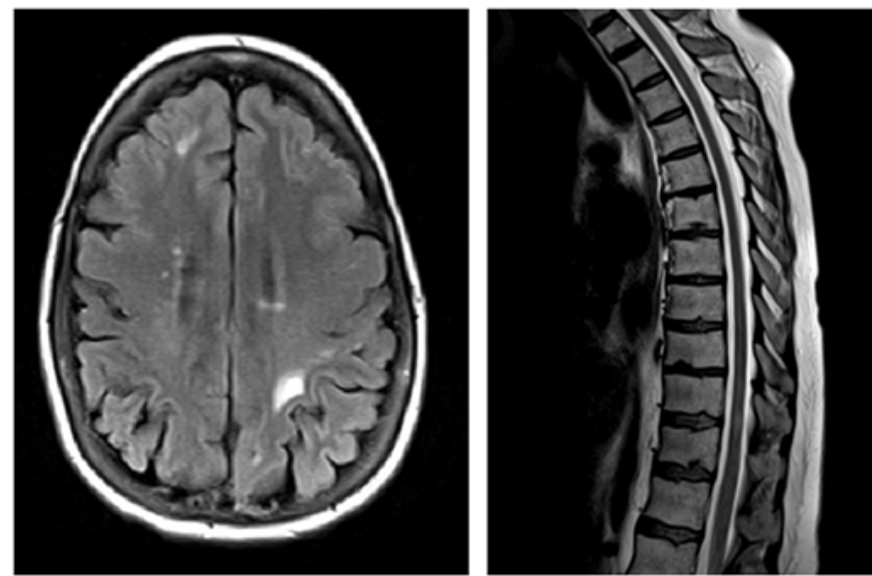

Figure 2

A. Multiple bilateral foci of abnormal signal hyper-intensity lesions were suspicious for multiple sclerosis.

B. Similar patchy areas of cord signal abnormality was noticed through the rest of the spinal cord.
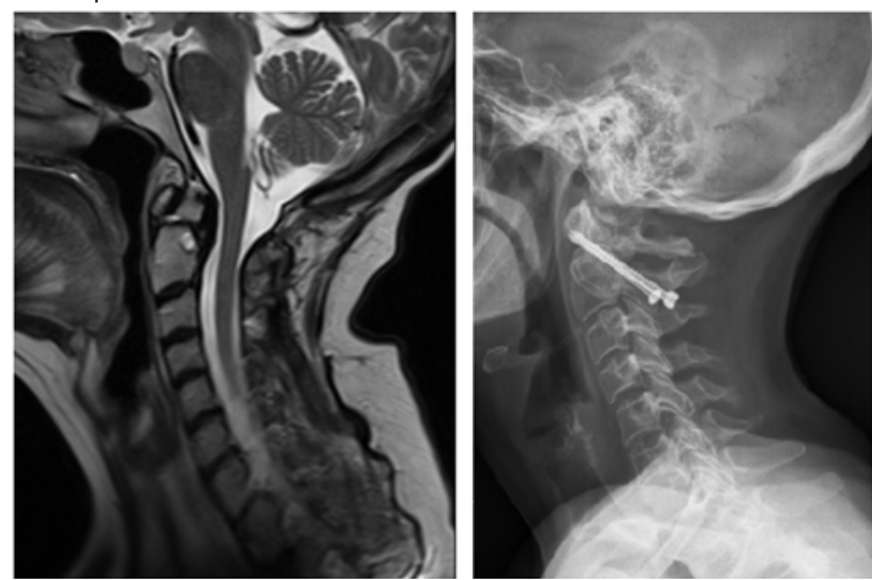

Figure 3

A. Spontaneous complete resolution of the synovial cyst at four months postoperatively with reduction in cord signal abnormality.

B. Lateral film illustrating stable fusion at long-term follow up.

\section{Discussion}

Cystic formations in degenerative spine are usually described in the lumbar region. ${ }^{4}$ They arise from the zygapophyseal joints and are commonly known as juxtafacet cysts. Since the cystic wall is lined by synovial cells, it is called a synovial cyst, which is typically filled with clear fluid. This is distinct from a cyst that is lined by fibrous connective tissue, called ganglion cyst, which is filled with gelatinous and highly viscous fluid. ${ }^{5}$ Juxtafacet cysts are usually a consequence of longstanding overstressed zygapophyseal joints which cause friction and local inflammation of the synovium. Fluid exudate accumulates within the joint space and leads to an out pouching of the synovium. It becomes symptomatic when the cyst interferes with traversing or adjacent neural tissues.

Although juxtafacet cysts in the cervical spine are uncommon, they may develop secondary to joint stress from progressive degenerative spondylosis. ${ }^{6}$ The changes in ligaments nature and cervical biomechanics after trauma may also play a role in expediting the process of cyst formation. In os odontoideum, the joint space between the ossicle and the odontoid process is a lined by synovium. In the context of an incapacitated transverse ligament, the synovial joint bears most of the atlantoaxial instability. A process of inflammation follows through repeated motion across this joint which eventually leads to synovial membrane overstretch injury and further inflammation and accumulation of fluid. There have been other mechanisms explaining possible etiologies for developing synovial cysts across the craniocervical junction and they include metaplasia, growth of synovial rests, growth of multi-potent mesenchymal cells, and mucinous degeneration of connective tissue.

The vast majority of cases of cystic degeneration at the craniocervical junction were treated with surgical decompression and cyst excision, as a result of compression-related cervical myelopathy. Different surgical approaches were used which include trans-oral decompression, $\mathrm{C} 1 / 2$ hemilaminectomy, posterior decompression and posterolateral approach. ${ }^{5-11}$ In regard to cystic association in os odontoideum, only four cases had been found in the literature for association with synovial cysts (Table 1). One of them was treated surgically with trans-oral approach and cyst excision followed by posterior instrumentation and fusion. ${ }^{12}$ Although the surgical outcome of this patient was good, this was not clinically different from the other two cases in which only atlantoaxial instrumentation was performed. ${ }^{13,14}$ In fact, the follow up of those two cases had shown significant regression of the synovial cyst. Therefore, the potential chance for cyst regression with only joint stabilization was suggested. Indeed, spontaneous regression of cysts has also been reported in degenerative cervical spine after a trial of external immobilization using a Philadelphia collar. ${ }^{15}$

Our case supports the aforementioned approach. We believe that treating the primary etiology, which is joint instability, prevents further stretch and irritation of the synovial joint and, hence, less fluid accumulation thereafter. But it is yet unclear how these cysts spontaneously regress after joint stabilization. The possibility of cyst rupture and fenestration into the epidural space had been proposed. ${ }^{16}$ However, we are not in favor of such mechanism and we think that cystic fluid is reabsorbed once the process of inflammation is subtle. This has been proven in experimental work for the role of antiinflammatory drugs in regression of juxtafacet cysts. ${ }^{17}$

The presence of MS was a perplexing coincidence, and we were uncertain about its impact on overall prognosis after surgery. However, the patient had made a substantial clinical improvement upon cyst regression. This finding supports that atlantoaxial stabilization for treating compressive synovial cyst was adequate. It is not clear whether the compressive synovial cyst had expedited her multiple sclerosis flare-up preoperatively. Nevertheless, the patient remained stable until the time of last follow up with no recurrent flare-up of multiple sclerosis. 
Table I Review of literature for os odontoideum with associated synovia cyst

\begin{tabular}{|c|c|c|c|c|c|c|c|}
\hline & Author,Year & $\begin{array}{l}\text { Age, } \\
\text { Gender }\end{array}$ & Clinical Features & $\begin{array}{l}\text { Dynamic } \\
\text { X-rays }\end{array}$ & Management & Outcome & $\begin{array}{l}\text { Follow up } \\
\text { (months) }\end{array}$ \\
\hline I & Aksoy et al. [I8] & $61 \mathrm{M}$ & $\begin{array}{l}\text { Stiffness of the legs with } \\
\text { loss of hand dexterity } \\
\text { function }\end{array}$ & NA & $\begin{array}{l}\mathrm{Cl}-\mathrm{C} 2 \text { laminectomy and } \\
\text { anterior fusion }\end{array}$ & NA & NA \\
\hline 2 & Chang et al. [13] & $45, M$ & $\begin{array}{l}\text { Left hand motor } \\
\text { weakness with } \\
\text { paresthesia }\end{array}$ & $\begin{array}{l}\text { Severe } \\
\text { instability }\end{array}$ & Posterior $\mathrm{Cl} / 2$ wiring & $\begin{array}{l}\text { Normal motor, } \\
\text { improved } \\
\text { paresthesia, } \\
\text { regression of the } \\
\text { cyst }\end{array}$ & 12 \\
\hline 3 & Kirk et al.[12] & $74, M$ & $\begin{array}{l}\text { Neck pain, Left } \\
\text { sided paresthesia, } \\
\text { hyperreflexia and } \\
\text { positive Hoffman's sign }\end{array}$ & $\begin{array}{l}\text { No } \\
\text { significant } \\
\text { instability }\end{array}$ & $\begin{array}{l}\text { Transoral excision of the } \\
\text { cyst followed by posterior } \\
\mathrm{CI} \text { lateral mass and } \mathrm{C} 2 \text { pars } \\
\text { instrumentation }\end{array}$ & $\begin{array}{l}\text { Entirely } \\
\text { asymptomatic }\end{array}$ & 18 \\
\hline 4 & Weng et al. [14] & $\mathrm{I}, \mathrm{F}$ & $\begin{array}{l}0 / 5 \text { in arms and } 1 / 5 \text { in } \\
\text { legs }\end{array}$ & Not done & $\begin{array}{l}\text { Closed reduction followed } \\
\text { by occipitocervical } \\
\text { instrumentation and fusion }\end{array}$ & $\begin{array}{l}\text { Asymptomatic } \\
\text { with normal gait, } \\
\text { regression of the } \\
\text { cyst }\end{array}$ & 3 \\
\hline
\end{tabular}

\section{Acknowledgments}

None.

\section{Conflicts of interest}

None.

\section{Funding}

None.

\section{References}

1. Pang D, Thompson DN. Embryology and bony malformations of the craniocervical junction. Childs Nerv Syst. 2011;27(4):523-564.

2. Crockard HA, Stevens JM. Craniocervical junction in inherited disorders: part of the syndrome or caused by disorder? Eur J Pediatr. 1995;154(7):504-512.

3. Guidelines for the Management of Acute Cervical Spine and Spinal Cord Injuries: Chapter 19, os odontoideum. Neurosurgery. 2002;50(3):S148-S155.

4. Lyons MK, Atkinson JL, Wharen RE, et al. Surgical evaluation and management of lumbar synovial cyst. J Neurosurg. 2000;93(1 Suppl):53-57.

5. Birch BD, Khandji AG, McCormick PC. Atlantoaxial degenerative articular cysts. $J$ Neurosurg . 1996;85(5):810-816.

6. Krauss WE, Atkinson JL, Miller GM. Juxtafacet cysts of the cervical spine. Neurosurgery. 1998; 43(6):1363-1368.

7. Miller JD, Al Mefty O, Middleton TH $3^{\text {rd }}$. Synovial cyst at the craniovertebral junction. Surg Neurol. 1989;31(3):239-242.

8. Choe W, Walot I, Schlesinger C, et al. Synovial cyst of dens causing cord compression. Case report. Paraplegia. 1993;31(12):803-807.
9. Fransen P, Pizzolato GP, Otten P, et al. Synovial cyst and degeneration of the transverse ligament:an unusual case of high cervical myelopathy. Case report. J Neurosurg. 1997;86(6):1027-1030.

10. Goffin J, Wilms G, Plets C, et al. Synovial cyst at the C1-C2 junction. Neurosurgery. 1992;30(6):914-916.

11. Zorzon M, Skrap M, Diodato S, et al. Cysts of the atlantoaxial joint: excellent long-term outcome after posterolateral surgical decompression. Report of two cases. J Neurosurg. 2001;95(1 Suppl):111-114.

12. Kirk HJ, Pik JH. A novel operative technique to manage a symptomatic synovial cyst associated with an os odontoideum. J ClinNeurosci. 2009;16(6):822-824

13. Chang H, Park JB, Kim KW. Synovial cyst in transverse ligament of the atlas in a patient with os odontoideum and atlantoaxial instability. Spine (Phila Pa 1976). 2000;25(6):741-744.

14. Weng C, Wang LM, Wang WD, et al. Bipartite atlas with os odontoideum and synovial cyst: case report and review literature. Spine (Phila Pa 1976). 2010;35(12):E568-E575.

15. Sagiuchi T, Shimizu S, Tanaka R, et al. Regression of an atlantoaxial degenerative articular cyst associated with subluxation during conservative treatment. J Neurosurg Spine. 2006;5(2):161-164.

16. Cecchi PC, Peltz MT, Rizzo P, et al. Conservative treatment of an atlantoaxial degenerative articular cyst: case report. Spine $J$. 2008;8(4):687-690.

17. Mattei TA, Goulart CR, McCall TD. Pathophysiology of regression of synovial cysts of the lumbar spine: the 'anti-inflammatory hypothesis'. Med Hypotheses. 2012;79(6):813-818.

18. Aksoy FG, Gomori JM. Symptomatic cervical synovial cyst associated with an os odontoideum diagnosed by magnetic resonance imaging: case report and review of the literature. Spine (Phila Pa 1976). 2000;25(10):1300-1302. 